\title{
BMJ Open Octogenarian patients' sleep and delirium experiences in hospital and four years after aortic valve replacement: a qualitative interview study
}

\author{
Hege Andersen Amofah (D) , ${ }^{1}$ Anders Broström, ${ }^{2,3}$ Irene Instenes, ${ }^{1}$ \\ Bengt Fridlund, ${ }^{1,4}$ Rune Haaverstad, ${ }^{1,5}$ Karel Kuiper, ${ }^{1}$ Anette Hylen Ranhoff, ${ }^{5}$ \\ Tone M. Norekvål (D) , 1,5 On behalf of the CARDELIR Investigators
}

To cite: Amofah HA, Broström A, Instenes I, et al. Octogenarian patients' sleep and delirium experiences in hospital and four years after aortic valve replacement: a qualitative interview study. BMJ Open 2021;11:e039959. doi:10.1136/ bmjopen-2020-039959

- Prepublication history for this paper is available online. To view these files, please visit the journal online (http://dx.doi. org/10.1136/bmjopen-2020039959).

Received 30 April 2020 Revised 11 December 2020 Accepted 15 December 2020

A) Check for updates

(c) Author(s) (or their employer(s)) 2021. Re-use permitted under CC BY-NC. No commercial re-use. See rights and permissions. Published by BMJ.

For numbered affiliations see end of article.

\section{Correspondence to} Professor Tone M. Norekvål; tone.merete.norekval@helsebergen.no

\section{ABSTRACT}

Objectives Sleep disturbances and delirium are frequently observed complications after surgical aortic valve replacement (SAVR) and transcutaneous aortic valve implantation (TAVI), especially in octogenarian patients. However, a knowledge gap exists on patient experiences of sleep and delirium. In particular, patients' long-term sleep and delirium experiences are unknown. This article explores and describes how octogenarian patients suffering from delirium after aortic valve replacement experience their sleep and delirium situation.

Design An explorative and descriptive design with a Iongitudinal qualitative approach was applied. Qualitative content analysis following the recommended steps of Graneheim and Lundman was performed.

Setting Patients were included at a tertiary university hospital with 1400 beds. Delirium and insomnia screening was performed at baseline and five postoperative days after aortic valve treatment. For qualitative data, 10 patients were interviewed 6-12 months after treatment with focus on delirium. Five of these patients were reinterviewed 4 years after treatment, with focus on their sleep situation.

Participants Inclusion criteria; age 80+, treated with SAVR or TAVI and had experienced delirium after treatment.

Results For the initial interview, we included five men and five women, four following TAVI and six following SAVR, mean age 83. One overarching theme revealed from the content analyses; Hours in bed represented emotional chaos. Whereas three subthemes described the patients' experiences with sleep and delirium, a cascade of distressful experiences disturbing sleep, the struggle between sleep and activity and elements influencing sleep. Four years after the treatment, sleep disturbances persisted, and patients still remembered strongly the delirium incidences.

Conclusions For octogenarian patients, sleep disturbances and delirium are long-term burdens and need a greater attention in order to improve patient care.

\section{INTRODUCTION}

Life expectancy for the general population has increased, and in particular, the number
Strengths and limitations of this study

- This study is the first to describe in detail octogenarian patients' sleep experiences in-hospital and 4 years after having postoperative delirium.

- Since octogenarian patients is an increasing population, this is a unique and relevant study providing important information for clinical practice and future studies.

- A limitation of the study might be the small number of patients interviewed.

> Considering the advanced age of the patients and the fact that they were reinterviewed after 4 years, this research contributes to the richness of the phenomena studied.

of octogenarians continues to grow. Since degenerative aortic stenosis is associated with ageing, the need for aortic valve replacement (AVR) is increasing. ${ }^{1}$ Age is no longer a contraindication for AVR via surgical aortic valve replacement (SAVR) or transcutaneous aortic valve replacement (TAVI). ${ }^{2}$ Introduction of new knowledge enabling minimally invasive aortic treatments has led to a paradigm shift in cardiac healthcare for the elderly. ${ }^{3}$ Although procedures are more refined, sleep disturbances and delirium remain frequent complications after cardiac surgery and negatively affect surgical recovery. ${ }^{4-7}$ In-hospital sleep disturbances can result from medical, environmental and psychosocial factors. ${ }^{8}$ It is important, therefore, to better understand postoperative sleep disturbances and delirium in order to improve short-term and long-term patient outcomes. ${ }^{9}$

Insomnia is characterised by difficulties in initiating or maintaining sleep, and is associated with significant distress or daytime impairment, despite adequate sleep opportunity. ${ }^{8}$ Changes in sleep patterns increase with 
age. ${ }^{10}$ Sleep disturbances are even more pronounced in octogenarian patients who, in general, sleep less at night but sleep more during daytime immediately following AVR. ${ }^{7}$ Sleep patterns during hospital stays can be studied either objectively (ie, by polysomnography or actigraphy) or subjectively (ie, by sleep questionnaires or sleep diaries). ${ }^{611}$ However, few, if any, studies have used interviews to assess sleep problems long after cardiac surgery. Rich qualitative information gained from interviews can complement quantitative data on sleep disturbances.

Delirium is a complication frequently observed in cardiac surgical patients. ${ }^{5}$ It is defined as an acute confusion state characterised by fluctuating mental status, inattention and disturbances in consciousness. ${ }^{12}$ There are three subtypes: hyperactive, hypoactive and mixed delirium. Hypoactive delirium is the most common type, has a worse prognosis and is difficult to recognise. ${ }^{12}$ Although the cause of delirium is not fully understood, it is known that impaired cognition and activities of daily living, advanced age, comorbidities, medications and major surgery are risk factors. ${ }^{13}$ Delirium may also be a risk factor for readmission and death in octogenarians after cardiac treatment. ${ }^{14}$

Sleep disruptions and delirium are known to be associated. ${ }^{15}$ This phenomenon was investigated already in 1999. In this study, Inouye et al found that sleep disruptions was one of the risk factors for developing a delirium. ${ }^{16}$ However, there is a knowledge gap in understanding sleep disturbances and delirium in octogenarians after AVR, especially understanding how sleep patterns and the experience of delirium might change over time. Studies reveal that insomnia affects quality of life due to night time difficulties and decreased daytime functioning. ${ }^{8}$ These aspects have not been studied from a long-term perspective. Also, few sleep studies have been performed using a qualitative approach while patients are in hospital. The focus of this study is the phenomenon postoperative delirium after SAVR and TAVI, and how sleep is perceived by the participants, over time. Therefore, the aim of this study was to explore and describe how patients who have delirium after AVR experience their sleep situation in a short and long-term perspective.

\section{METHODS}

\section{Design and setting}

The study used an explorative and descriptive design, qualitatively assessing patients' experiences longitudinally. We interviewed the same patients twice; the first time 6-12 months after treatment, and the second time 4 years after treatment. It was performed in the cardiothoracic surgical centre of a 1400-bed tertiary university hospital that serves 1.1 million inhabitants in western Norway. To ensure appropriate reporting, the study is in accordance with the Consolidated criteria for Reporting Qualitative research checklist. ${ }^{17}$

\section{Selection and description of participants}

Patients were included from our prospective cohort study, 'Delirium in octogenarians undergoing cardiac surgery or intervention (CARDELIR)'. ${ }^{5}$ Inclusion criteria in that study were age of 80 years or older, having severe symptomatic AS, being accepted for SAVR or TAVI, being able to speak and understand Norwegian, and granting written informed consent. The incidence of delirium was high in CARDELIR, with $44 \%$ after TAVI and $66 \%$ after SAVR. ${ }^{5}$ As this was at the early era of the TAVI treatment, both groups stayed in the hospital for 5 days or more. Only one patient of the main study $(n=143)$ left the hospital earlier. To assess delirium, we used the Confusion Assessment Method (CAM), a brief four-step assessment. CAM is based on operationalised criteria derived from the Diagnostic and Statistical Manual of Mental Disorders and assesses four features: (1) acute-onset and fluctuating course, (2) inattention, (3) disorganised thinking and (4) altered level of consciousness. Delirium is diagnosed when features 1 and 2 are present and either 3 or 4 are displayed. ${ }^{18}$ For the present study, potential participants were patients who had experienced delirium after SAVR or TAVI, remembered it, and had no cognitive impairment before the treatment or at the 6-month follow-up (table 1).

For the first interview, based on initial assessment of most eligibility criteria, 22 patients were eligible for inclusion. They were recruited at the 6-month follow-up at the cardiac outpatient clinic. Twelve patients were excluded (eg, did not remember having any delirium episodes, did not consent to participate, or withdrew their consent). Altogether, five men and five women were included for the initial interview; four received TAVI and six received SAVR. For the follow-up interview, the same 10 patients were contacted by postal mail 4 years post surgery. Four men and one woman agreed to participate $(\mathrm{SAVR}=3$; TAVI=2; figure 1).

The CAM was administered at baseline (the day before treatment) and daily for the first five postoperative days after SAVR or TAVI. Cognitive function was assessed using the 11-item version of the Mini-Mental State Examination (MMSE) where $<27$ indicates cognitive impairment. ${ }^{19}$ MMSE performance was assessed at baseline and at the 6-month follow-up. The Sleep Sufficient Index ${ }^{20}$ and the 3-item Minimal Insomnia Symptom Scale (MISS) were used to document self-reported sleep at baseline, the first five postoperative days, and at the 6-month follow-up. ${ }^{21}$

\section{Patient and public involvement}

No patients were involved in the design and implementation of the study. However, patient self-report is at the very core of the CARDELIR study. ${ }^{571422}$ There are plans to disseminate the results of the research to the patient community through patient organisations.

\section{Data collection}

Two interview rounds were done, one 6-12 months after discharge (initial interview) and another 4 years 
Table 1 Characteristics of octogenarian surgical aortic valve replacement (SAVR) or transcutaneous aortic valve replacement (TAVI) patients included in the qualitative interview study $(n=10)$

\begin{tabular}{|c|c|c|c|c|c|c|c|c|}
\hline \multirow[b]{2}{*}{ Characteristics } & \multicolumn{2}{|l|}{ Baseline* } & \multicolumn{2}{|c|}{ First 5 postoperative days } & \multicolumn{2}{|c|}{ After 6 months } & \multicolumn{2}{|c|}{ After 4 years } \\
\hline & $\begin{array}{l}\text { Mean or } \\
\text { count }\end{array}$ & $\begin{array}{l} \pm \text { SD or } \\
(\%)\end{array}$ & $\begin{array}{l}\text { Mean or } \\
\text { count }\end{array}$ & \pm SD or $(\%)$ & $\begin{array}{l}\text { Mean or } \\
\text { count }\end{array}$ & \pm SD or $(\%)$ & $\begin{array}{l}\text { Mean or } \\
\text { count }\end{array}$ & \pm SD or $(\%)$ \\
\hline Age (years) & 83.0 & 2.2 & & & & & 86.8 & 2.2 \\
\hline \multicolumn{9}{|l|}{ Sex } \\
\hline Male & 5 & (50) & 5 & (50) & 5 & (50) & 4 & (80) \\
\hline Female & 5 & (50) & 5 & (50) & 5 & (50) & 1 & (20) \\
\hline \multicolumn{9}{|l|}{ Marital status } \\
\hline Married & 5 & (50) & 5 & (50) & 5 & (50) & 2 & (40) \\
\hline Divorced & 1 & (10) & 1 & (10) & 1 & (10) & 0 & (0) \\
\hline Widowed & 4 & (40) & 4 & (40) & 4 & (40) & 3 & (60) \\
\hline \multicolumn{9}{|l|}{ Cohabitation status } \\
\hline Living alone & 5 & (50) & 5 & (50) & 5 & (50) & 3 & (60) \\
\hline Living with spouse & 4 & (40) & 4 & (40) & 4 & (40) & 2 & (40) \\
\hline Living with others & 1 & (10) & 1 & (10) & 1 & (10) & 0 & (0) \\
\hline Treatment & & & & & & & 2 & (40) \\
\hline TAVI & 4 & (40) & 4 & (40) & 4 & (40) & 2 & (40) \\
\hline SAVR & 6 & (60) & 6 & (60) & 6 & (60) & 3 & (60) \\
\hline MMSE & 27.4 & 3.7 & & & 27.3 & 3.5 & & \\
\hline HADS & 9.6 & 6.0 & & & & & & \\
\hline Charlsons Comorbidity Index & 2.2 & 1.1 & & & & & & \\
\hline \multicolumn{9}{|l|}{ Time in ICU } \\
\hline $\mathrm{TIO}$ (hours) & & & 64.8 & 139.3 & & & & \\
\hline MIO (hours) & & & 28.5 & 49.1 & & & & \\
\hline \multicolumn{9}{|l|}{ Actigraphy } \\
\hline Sleep time, night (hours) $†$ & & & 5.9 & 1.9 & & & & \\
\hline Sleep time, day (hours) $\dagger$ & & & 10.8 & 2.6 & & & & \\
\hline MISS & 2.8 & 2.4 & 4.8 & 3.0 & 6.7 & 2.3 & & \\
\hline \multicolumn{9}{|l|}{ SSI } \\
\hline Estimated sleep need (hours) & 7.4 & 1.3 & & & 7.4 & 0.9 & & \\
\hline Total sleep per night (hours) $\dagger$ & 6.7 & 1.5 & & & 6.7 & 1.3 & & \\
\hline \multicolumn{9}{|l|}{ Premedication } \\
\hline Oksazepam & 3.0 & (30) & & & & & & \\
\hline Morphine scopolamine & 6.0 & (60) & & & & & & \\
\hline None & 1.0 & (10) & & & & & & \\
\hline \multicolumn{9}{|l|}{ Postoperative medication required } \\
\hline Loop diuretics required & & & 10.0 & $(100)$ & & & & \\
\hline Opioids required & & & 10.0 & $(100)$ & & & & \\
\hline Hypnotics required & & & 6.0 & (60) & & & & \\
\hline
\end{tabular}

MMSE measures general cognitive function, with maximum score of 30 points. Possible score $<27$ indicates cognitive impairment. MISS Possible Sum score: 0-3=no insomnia, 4-6=subclinical insomnia, 7-9=moderate insomnia, 10-12=severe insomnia.

*Baseline, the day before surgery.

†These data are from the prospective cohort study. ${ }^{5}$

HADS, Hospital Anxiety and Depression Scale; ICU, intensive care unit; MIO, medical intensive care (TAVI patients); MISS, Minimal Insomnia

Symptom Scale; MMSE, Mini-Mental State Examination; SSI, Sleep Sufficiency Index; TIO, thorax surgical intensive care (SAVR patients).

post surgery (follow-up interview). The initial interview focused on how patients' experienced delirium during the early postoperative phase. The interview guide was developed based on clinical experiences in the research group. The interview guide was semistructured and open ended to enrichen the responses, and piloted by the research team (box 1). The interviews lasted 30-40 min. For this initial interview, seven patients were interviewed 
Eligible patients:

$\mathrm{N}=22$

\section{Initial interview}

Invited at 6 months postdischarge:

$\mathrm{n}=13$

Did not remember having experienced delirium: $n=5$

Did not consent: $n=2$

Invited at 12 months postdischarge:

$$
\mathrm{n}=9
$$

Did not remember having experienced delirium: $n=1$

Did not consent: $n=1$

Withdrew consent: $\mathrm{n}=1$

\section{Included for} interview: $\mathrm{n}=6$

\section{Dead: $\mathrm{n}=1$}

\section{Second interview}

\section{Did not reposnd: $\mathrm{n}=3$}

Not able to participate: $n=1$

Figure 1 Participant selection. Flow chart for selecting participants included in the study. Surgical aortic valve replacement or transcutaneous aortic valve replacement patients included at the initial interview 6-12 months after discharge and the follow-up interview 4 years after discharge. 
Box 1 Guide for the interviews conducted 6-12 months post discharge (initial interview) and 4 years after aortic valve treatment (follow-up interview).

\section{Initial interview:}

1. In which situations did you first experience a change in your condition after the heart surgery or intervention?

2. Could you please tell me how you experienced this?

- Did something in your surroundings influence your experience?

- Did you at any time understand that your experiences were unreal?

3. For how long did you feel the situation/condition last?

4. How did it feel when the delirium ended?

- Did the condition occur again during your hospitalisation?

5. How did you experience the nurse's behaviour towards you during your delirium?

6. Were you able, or given a chance, to speak to anyone on the nursing staff about your experiences?

7. Have you thought about your experiences after being discharged from the hospital?

8. Have you been able to share your experiences with others?-Family, relatives, friends, etc?

\section{Follow-up interview:}

Think back on the cardiac surgery that you underwent about 4 years ago.

1. Can you describe how your sleep situation was in the hospital after surgery?

Alternative follow-up questions:

- Can you describe how sleep was distributed throughout the night?

- Was there anything special that affected (improved or worsened) your sleep in the hospital?

- Could you tell me if you had pain that affected your sleep situation?

- Can you describe how you look at the healthcare provider's role in relation to your sleep in the hospital?

- Can you tell me how you thought about your sleep situation at the hospital?

2. Can you describe how your sleep situation was after you returned home?

Alternative follow-up questions:

- Was there anything special that affected your sleep situation?Could you tell me if you had pain that affected your sleep situation?

- Could you describe how it was initiating sleep in the evening?

- Can you describe how sleep was distributed throughout the day and night?

How did your sleep situation change during the first few months?

- Can you tell me your thoughts about your sleep situation in the first few months?

3. Can you describe how your sleep situation is now, a long time after your cardiac surgery?

Alternative follow-up questions:

- Is there something special that affects your sleep now?

- Can you tell me if you have pain that affects your sleep situation?

Can you describe how it is for you to fall asleep in the evening?

- Can you tell me how you think about your sleep situation?

- Do you wake up at night?

What has affected your sleep situation?

4. Can you describe now, a long time after your cardiac surgery, how your sleep situation affects your daily life?

Alternative follow-up questions:

How is your ability to work influence things affected?

Continued

\section{Box 1 Continued}

How does sleep affect how you feel emotionally?

How is your ability to interact with your relatives affected?

in their home, and three patients were interviewed in an office at the university hospital. ${ }^{23}$ Prior to the interviews, the patients were explained the purpose of the interview. The interviews lasted for 30-40 min. They were conducted, audio recorded and transcribed verbatim by the third coauthor, an experienced nurse specialised in geriatric care. Preliminary findings from this initial interview suggested that more long-term information was needed about patients' sleep experiences after delirium. This revelation guided the development of content for the follow-up interview guide.

The 4-year follow-up interview focused on how patients experience their sleep situation from a long-term perspective, both when they were in hospital and after discharge. A second interview guide was developed, and after pilot testing it, the final version was compiled (box 1). Four of the patients were interviewed at home, and one in an office at the university hospital; interviews lasted 30-40 min. They were conducted, audio recorded and transcribed verbatim by the first author, an experienced nurse specialised in cardiovascular nursing and working on the thoracic surgical ward.

\section{Data analysis}

The recommended steps of Graneheim and Lundman ${ }^{24}$ guided the qualitative content analysis of patient interviews. This approach is inductive and open minded. The authors read and discussed the transcribed text several times in order to get a global sense of the content. This laid ground for the follow-up interview guide (box 1), and thereafter the initial data were reanalysed. The transcribed text from each interview of the two interview rounds was read, and the two were combined. The first analysis step involved identifying similar meaning units from the global text. Then, the meaning units were condensed and labelled with a code. Thereafter, codes with similar content were grouped and structured into categories; these categories were interpreted into subthemes. The first and the third author read the transcribed interviews independently and followed closely the analytical process in reaching a consensus. ${ }^{24}$ They coded the transcripts and developed themes before they came together to compare, discuss and resolve. Co-authors were consulted on specific points in the analysed text. Finally, an overarching theme describing the latent content of the text emerged (table 2). Both manifest and latent analysis were carried out. The manifest content of the text is related to the visible and obvious components of the interview (what the patients said). Latent content analysis involves an interpretation of the underlying meaning of the text. ${ }^{24}$ 
Table 2 Examples of how quotations were used in the analysis procedure to produce themes

\begin{tabular}{|c|c|c|c|c|}
\hline \multicolumn{5}{|c|}{ Overarching theme: Hours in bed represented emotional chaos } \\
\hline Meaning unit & Condensed meaning unit & Code & Category & Subtheme \\
\hline $\begin{array}{l}\text { 'It might have been when I was going to sleep again, } \\
\text { and then it just reappeared...' }\end{array}$ & $\begin{array}{l}\text { The dreams came when I was going } \\
\text { to sleep }\end{array}$ & Dreaming in hospital & $\begin{array}{l}\text { Disruptions from } \\
\text { nightmares }\end{array}$ & \multirow{2}{*}{$\begin{array}{l}\text { A cascade } \\
\text { of distressful } \\
\text { experiences } \\
\text { disturbing sleep }\end{array}$} \\
\hline $\begin{array}{l}\text { 'I remember I could not breathe, and that was } \\
\text { horrible... I think... not being able to breathe...' }\end{array}$ & $\begin{array}{l}\text { It was a terrible feeling not being } \\
\text { able to breathe }\end{array}$ & Breathing problems & $\begin{array}{l}\text { Sleep disturbances from } \\
\text { physical discomfort and } \\
\text { anxiety }\end{array}$ & \\
\hline 'I struggled with sleep at night in the hospital.' & I slept badly at the hospital & $\begin{array}{l}\text { Night time sleep in } \\
\text { hospital }\end{array}$ & \multirow[t]{3}{*}{$\begin{array}{l}\text { Imbalance of daytime and } \\
\text { night time sleep }\end{array}$} & \multirow{5}{*}{$\begin{array}{l}\text { The struggle } \\
\text { between sleep } \\
\text { and activity } \\
\text { continued }\end{array}$} \\
\hline $\begin{array}{l}\text { 'And when it was day and you sat in the chair, you } \\
\text { dozed, and when the night came, you did not need } \\
\text { much sleep ...' }\end{array}$ & $\begin{array}{l}\text { I slept a lot during daytime, so } \\
\text { at night I did not need too much } \\
\text { sleep... }\end{array}$ & $\begin{array}{l}\text { Daytime sleep in } \\
\text { hospital }\end{array}$ & & \\
\hline $\begin{array}{l}\text { 'I still have trouble sleeping ... sleeping is not my } \\
\text { strongest field...' }\end{array}$ & I still have trouble sleeping & Night time sleep now & & \\
\hline $\begin{array}{l}\text { 'I dozed, you know; that's probably why I didn't sleep } \\
\text { very well ...' }\end{array}$ & I dozed, and did not sleep very well & $\begin{array}{l}\text { Quality of sleep in } \\
\text { hospital }\end{array}$ & \multirow{2}{*}{$\begin{array}{l}\text { Numerous insomnia } \\
\text { symptoms }\end{array}$} & \\
\hline $\begin{array}{l}\text { 'I have the impression that I sleep a little worse now, I } \\
\text { wake up easily ...' }\end{array}$ & I sleep worse now; I wake up easily & Quality of sleep now & & \\
\hline $\begin{array}{l}\text { '... but it wasn't better anyway, if I didn't sleep during } \\
\text { the day, I don't think the night was better...' }\end{array}$ & $\begin{array}{l}\text { It did not help staying awake during } \\
\text { the daytime }\end{array}$ & Sleep during daytime & \multirow[t]{3}{*}{ Physical sleep distractions } & \multirow{4}{*}{$\begin{array}{l}\text { Diverse elements } \\
\text { influencing the } \\
\text { quality of sleep }\end{array}$} \\
\hline $\begin{array}{l}\text { 'And then it was that I had to stay on my back all the } \\
\text { time. That I could not turn around ...' }\end{array}$ & $\begin{array}{l}\text { The problem was that I had to sleep } \\
\text { on my back }\end{array}$ & Sleeping position & & \\
\hline $\begin{array}{l}\text { 'and then I was completely crazy. } \\
\text { I remember from the hospital that I responded to } \\
\text { the sleep medication. So it will not be applicable } \\
\text { anymore. To have something to sleep on, that was } \\
\text { not ....' }\end{array}$ & $\begin{array}{l}\text { I remember I got 'crazy' after the } \\
\text { sleep medication; I will not use that } \\
\text { again. }\end{array}$ & Sleep medication & & \\
\hline $\begin{array}{l}\text { 'Also there was a patient who was very fussy at night. } \\
\text { So he woke me up if I dipped off.' }\end{array}$ & $\begin{array}{l}\text { Another patient talked a lot during } \\
\text { the night and woke me up }\end{array}$ & Other patients & $\begin{array}{l}\text { Environmental sleep } \\
\text { interruptions }\end{array}$ & \\
\hline
\end{tabular}

\section{FINDINGS}

Sleep experiences of octogenarian patients were characterised by an overarching theme: Hours in bed represented emotional chaos. Findings are presented below by three subthemes with two categories each (table 2, figure 2). Quotations are presented to illustrate the themes.

\section{A cascade of distressful experiences disturbing sleep}

In hospital, nightmares dominated the patients' sleep, an unpleasant experience they readily recalled in a longterm perspective. Physical and psychological discomforts were also prominent features of their sleep disturbances, some of which persisted 4 years post surgery.

\section{Disruptions from nightmares}

Patients' nightmares led to poor quality of sleep. Patients alternated between dreaming and reality most of the time in hospital. Surrounding objects and people were described as coming and going, and healthcare professionals were sometimes seen as threats. They described being confused, in a strange situation, or in a daze. Patients expected the nightmares to return, and even though they were tired, they were afraid to fall asleep at night. As soon as they closed their eyes, nightmares occurred. Nightmares also woke them when they did manage to sleep.

During the four weeks I was admitted [in hospital], I was continuously asleep and in a dream [-like state]...

I was far away... (Participant 1$)$

The nightmares' horrific content was so memorable that patients were able to recall it 4 years later. Patients described their dreaming as being more 'normal' at 


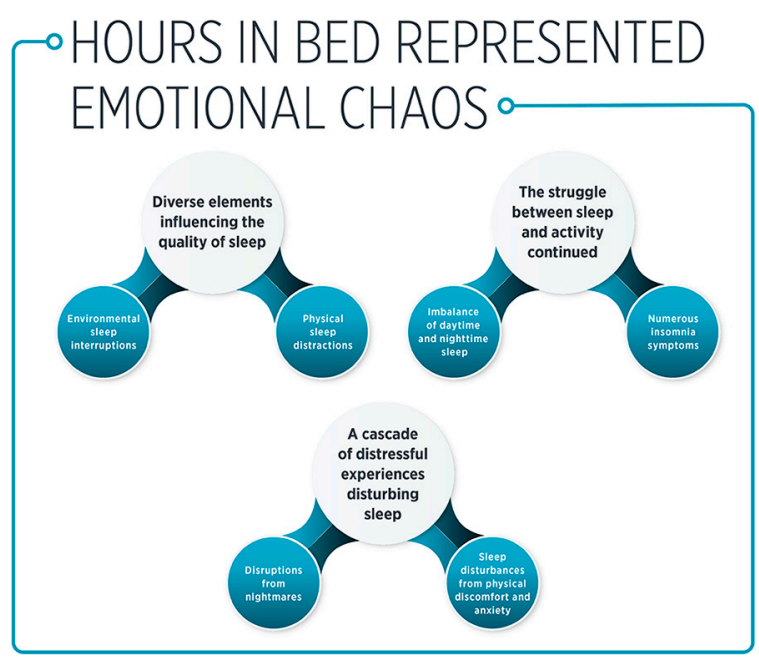

Figure 2 Findings from qualitative content analysis of participant interviews. Octogenarian patients' sleep experiences after delirium could be characterised by three subthemes, all under the umbrella of the overarching theme; hours in bed represented emotional chaos.

the 4-year follow-up, not like the nightmares they experienced in hospital. Moreover, their dreaming did not influence their overall sleep as much as it did when they were in hospital soon after surgery.

Fortunately, it's better at night now. Not great sleep, but no nightmares. (Participant 2)

\section{Sleep disturbances from physical discomfort and anxiety}

In hospital, patients said physical discomfort made them anxious, and they felt lonely. They heard people talking, but did not see any healthcare professionals nearby. This was a problem, as patients really needed somebody to pay close attention to them. Because they were worried, they also slept poorly.

You felt sometimes you could need a hand to hold ..., just for a moment ... you felt completely alone and without... (Participant 3)

Loneliness and sadness persisted as sleep-disturbing elements 4 years later, in addition to problems initiating sleep and waking up during the night because of loneliness and sadness.

I become really sad, in a... I don't know what to call it, but it's like I... [break] I might feel the need to complain, actually ... and it appears, not only at night when I sleep, in the middle of the day too. So I can wake up because of it at night too. (Participant 4)

In addition, patients experienced prominent breathing problems while in hospital. Pain from the surgery wound and a general feeling of physical discomfort affected their sleep. Even 4 years later, patients recalled their feelings of physical discomfort and anxiety when they were hospitalised. Some participants stated that the physical discomfort continued as a sleep-disturbing factor in the long term, if I lie on my back I can wake up gasping slightly after my breath (showing with gasp sound), I have to lie on my side. (Participant 5)

The struggle between sleep and activity continued

Both at the 6-12 month interview and at the follow-up interview 4 years post surgery, patients recalled that their in-hospital sleep-wake pattern was disturbed.

\section{Imbalance of daytime and night time sleep}

Patients emphasised that their reduced night time sleep quality was a problem in hospital, leading to reduced energy and more sleeping during the day and decreased activity when they were awake. This meant that they stayed in bed most of the time while in hospital.

I struggled with sleep at night in the hospital.

(Participant 5)

Four years later, participants still said they had reduced night time sleep quality and like in the 6-12 month interview, they also said this resulted in reduced energy and increased daytime sleep. They also felt that this resulted in problems initiating sleep now.

I still have trouble sleeping... sleeping is not my strongest point. (Participant 3)

\section{Numerous insomnia symptoms}

In hospital, initiating sleep and waking up at night were the most prominent insomnia problems reported. Even though patients were tired in the evening and wanted to sleep, they were unable to do so. Patients did not sleep deeply; instead, they just dozed lightly and woke up frequently. They woke up early in the morning due to hospital routines. This was not problematic, however, as they normally woke up early anyway.

It was falling asleep in the evening, it was the worst, it could take a long time ... (Participant 6 )

Participants continued to experience insomnia symptoms 4 years later.

...but I have problems initiating sleep...I do... it's really annoying. (Participant 7)

...usually I wake up three to four times during the night, and it's poor sleep when you wake up so many times... (Participant 3)

\section{Diverse elements influencing the quality of sleep}

Patients described several factors that were sleepdisturbing elements. They tried to understand these and solve the problems arising from them using different strategies.

\section{Physical sleep distractions}

While in hospital, patients viewed medical-technical equipment as sleep-disturbing elements, both physically and emotionally. Sedatives administered in this context were also negatively perceived and sleep disrupting, 
because they failed to make patients sleep better. Moreover, patients believed that the sedatives and anaesthesia caused their nightmares. Being unable to sleep on their side or to move because of the surgical wound and being connected to equipment were sleep disturbing. Narrow beds, hard mattresses and uncomfortable pillows were also perceived as sleep-disturbing elements.

... then I woke up feeling like I was tied up by many snakes. So there was one ... no, not living snakes but medical cables. And it rolled around my legs and I could not ... I just tore it away. I think it was the urine catheter, but it did not hurt. (Participant 8)

Patients eagerly anticipated going home, believing the domestic environment would promote better sleep. However, participants' poor sleep patterns continued after arriving home, even persisting 4 years later. Painrelated and breathing-related sleep disturbances were also present in the long term. Having to use the toilet at night was described as a sleep-disturbing element. Some participants used sleeping pills, but they said that it did not help them sleep better.

At first I was at the local hospital for a week, and then I was in a nursing home before I got home. So I was away from home for a long time, and I thought; 'Oh, it will be good to come home to my own bed,' but it did not get much better ... (Participant 3)

\section{Environmental sleep interruptions}

Noise from other patients and staff interrupted patients' sleep in hospital at night, like when others needed assistance and medical treatment. Visible body fluids, like blood and vomit, sometimes interrupted sleep for some patients, as did patients talking among themselves or to hospital staff. Patients who were not comfortable sharing a room with other patients found that this also interrupted sleep patterns. Patients' strategies for dealing with these interruptions would be to sit in a chair at night, which also helped them overcome breathing problems, pain and failing to find a comfortable sleeping position.

...but it was not better anyway, if I did not sleep during the day. I didn't think the night was better. (Participant 3)

At the 4-year interview, participants were still able to recall these in-hospital sleep interruptions. They were also aware they still had these problems, but now they had different sleep-promoting strategies. They were aware of disruptions in night time sleep caused by daytime sleep, which they dealt with by reading a book and focusing on breathing, for example. They were also aware that some foods could negatively affect their sleep. Moreover, physical activities, like going for a walk or riding a bike, were effective strategies to help them sleep.

It may have something to do with the food $\ldots$ because I notice if I do not eat a little extra in the evening, then I get a stomach ache when I'm lying in bed at night. (Participant 1)

\section{DISCUSSION}

To our knowledge, no previous studies have described and analysed in detail octogenarian patients' in-hospital and present sleep experiences 4 years after having postoperative delirium. An important finding was that the patients identified suffering from multiple symptoms, they consistently described their in-hospital sleep situation as poor and dominated by nightmares and discomfort, such as pain. Sleeping less at night led to more sleeping and inactivity during the day. Patients after both TAVI and SAVR described the same problems. Participants still remembered these problems 4 years after discharge, and these problems persisted. Moreover, loneliness and anxiety were identified as challenges.

Sleep is an important part of the recovery process, and sleep disturbances may have negative effects on general health status. ${ }^{10}$ Despite their advanced age and long retention period, patients recalled their poor sleep and delirium experiences in hospital 4 years later, which shows how intense these experiences were. This is in contrast to previous studies on delirium recall, in which younger patients were more likely to recall delirium than older patients. ${ }^{25}$ In-hospital, sleep may generally be disturbed by medical, environmental and psychosocial factors. ${ }^{8}$ In particular, following surgery it can be difficult to maintain a normal sleep-wake pattern. ${ }^{67}$ In the present study, nightmares, physical discomfort and physical and environmental distractions appeared to amplify disturbed sleep-wake patterns of octogenarian patients after postsurgical delirium. This was especially the case for initiating sleep and waking up at night, which the patients attributed to nightmares. Many clinicians believe a relationship exists between reduced sleep and delirium, although this relationship has not yet been established. ${ }^{11}$ A systematic review of quantitative and qualitative research shows that disrupted sleep patterns can contribute to delirium. ${ }^{26}$ Because patients in the present study described how delirium disturbed their sleep, this adds to what is already known about disrupted sleep patterns and delirium. Studies on sleep and delirium in the ICU highlight the importance of reducing ambient light and noise, and encouraging patients to use earplugs and eye masks to promote sleep and reduce delirium. ${ }^{27} 28$ However, in the present study, patients appeared to feel more anxious and alone because of their nightmares and physical discomfort, mainly from breathing problems. Combined with being able to hear but not see nearby healthcare professionals, this made them strongly desire a reassuring hand. Thus, these observations suggest that octogenarian patients likely need more attention from healthcare professionals soon after surgery. An Acute Care for the Elderly (ACE) unit, or elements thereof, could possibly accommodate the special needs of these 
octogenarian patients. The ACE units are based on four elements; patient-centred care, specially designed environment, review of medical care and planning for discharge. ${ }^{29}$ Nevertheless, it must be taken into consideration if delirium is still a frequent complication after TAVI whit changes in the TAVI treatment, shortened time in the ICU and rapid discharge.

Since images of hospital medical equipment had encroached on our patients' nightmares, removing the equipment as soon as possible could be an important measure in moderating delirium and improving sleep. Reduced physical activity is a predictor of sleep disturbances ${ }^{25}$ and studies show that early mobilisation in the ICU also improves sleep and prevents delirium. ${ }^{27} 30$ Patients were constrained by medical equipment, and therefore inactivity could perhaps partially explain the poor sleep quality and delirium in our patients. Therefore, one sleep-improving measure would be to remove urinary catheters. In patients with TAVI, avoidance of the urinary catheter has been seen to improve the outcome. ${ }^{2231}$

Previous studies on sleep and delirium show that avoiding excessive daytime sleep is another important measure to improve the quality of sleep. ${ }^{2730}$ This is consistent with our participants' description in that initiating sleep and night waking were related to physical discomfort and daytime sleeping. They described a vicious cycle of reduced quality of night time sleep leading to tiredness and intermittent napping during the day and fragmented sleep at night. ${ }^{1032}$ These problems persisted even 4 years after hospital discharge. Thus, helping patients to avoid daytime sleep and encouraging their own efforts and strategies to avoid daytime sleep are important, for example by engaging in more physical exercise and social and cognitive activities.

Studies on delirium show that sedatives (benzodiazepines and Z-hypnotics) may facilitate sleep, but can contribute to confusion and delirium. Use of benzodiazepines is also associated with daytime sedation and rebound insomnia, ${ }^{33}$ suggesting that they should be used cautiously and selectively in older patients. ${ }^{12}$ These observations are consistent with what our patients described, use of sedatives failed to improve the quality of their sleep and may have contributed to their delirium.

Although some patients experienced they had no problems falling asleep before surgery, all described they had problems afterwards. However, it also should be considered that sleep changes with age and older adults often have difficulties initiating sleep. ${ }^{10}{ }^{32}$ Therefore, just the fact that these patients were older when interviewed at the follow-up could explain the new sleeping problems they described. Still, chronological age alone is not an independent predictor of sleep disturbances. Other risk factors include depressed mood, widowhood and loneliness, ${ }^{25}$ all covariates of increasing age. Some participants became widowed after the surgery (table 1). Losing their mate caused them to be lonely, to have trouble initiating sleep, and to wake up at night.
Physical illness is another risk factor for sleep disturbances in older adults, ${ }^{25} 32$ one related to normal ageing. ${ }^{10}$ This is consistent with our participants' reports of waking up at night because of pain or breathing problems and waking up frequently to go to the toilet. Participants' MISS scores at 6 months were worse than before surgery, moving from no insomnia to subclinical and moderate insomnia (table 1). These observations highlight the importance of treating the underlying problem in order to promote better sleep. Research is needed to determine the precise mechanisms through which these factors influence sleep over time. ${ }^{25}$ The CARDELIR study revealed that delirium are associated with cognitive function and treatment type. Moreover, risk assessment before surgery will also be of great importance in this patient group.

\section{METHODOLOGICAL CONSIDERATIONS}

In qualitative content analysis, trustworthiness is often discussed in terms of credibility, dependability, confirmability and transferability. ${ }^{24}$ The manifest and latent analysis varied in the level of abstraction, as the latent analysis constitute a further in-depth analysis. This strengthened the trustworthiness of our analysis. To achieve credibility, we used qualitative content analysis, describing patient's personal experiences of sleep and postoperative delirium. The interviewees' gender, age and AVR treatment contributed to the richness of the phenomena studied. However, it must be considered that the accuracy of octogenarians' memories after 4 years could pose a limitation. Different authors performed the two interviews, further strengthening trustworthiness. This also brought heightened scrutiny both to the data collection and analysis procedures, because we were aware that the different backgrounds might bring different biases. The first author encouraged dialogue and agreement among coauthors to find the best way to label and sort data, and what the best categories and themes were to describe the data. We were aware that robust dependability requires that we take into account the degree to which data could change over time and that we ensure that our decisions were stable during the analysis process. We were vigilant in keeping our data consistent over the extensive collection period. ${ }^{24}$ Confirmability was achieved by following all the steps in the analytical process. We guarded against prior understanding bias by reading closely the interviews and field notes during the analysis and by discussing these with the coauthors. The findings from this study are transferrable to other patient groups of comparable age. Although we interviewed a small number of patients, we believe this is not a major limitation of the study, considering the advanced age of the patients. However, in this older population, it must be considered that other aetiologies may impact their sleep, such as pain, medications and comorbidities. In long term, it is difficult to determine what is related to the surgery versus other aetiologies. Nevertheless, with the increasing population of octogenarian patients, the findings provide important information for clinical practice and future studies. 


\section{CONCLUSIONS}

Sleep disruption and delirium are major postsurgical complications. The symptoms and unmet needs described from these patients are likely what contributed to delirium. Both SAVR and TAVI patients had the same problems even though they had different procedures and different postoperative care. Moreover, some of these disturbances persisted in a long term. Therefore, in order to reduce older SAVR and TAVI patients' postsurgical delirium, physical and emotional discomfort, and daytime sleep, it can be argued that healthcare professionals need to pay more attention and seek longlasting strategies, to treating and understanding sleep quality and delirium in older surgical patients. One important delirium-preventing measure could be to focus on early ambulation, which might also produce better sleep experiences in both short and long terms. Moreover, increased efforts need to be spent towards informing older surgical patients before surgery and before discharge that sleep disturbances and delirium might occur.

\section{Author affiliations}

${ }^{1}$ Department of Heart Disease, Haukeland University Hospital, Bergen, Norway ${ }^{2}$ School of Health and Welfare, Jönköping University, Jonkoping, Sweden ${ }^{3}$ Department of Clinical Neurophysiology, Linkoping University Faculty of Medicine, Linkoping, Sweden

${ }^{4}$ Department of Health and Caring Sciences, Linnaeus University Faculty of Health and Life Sciences, Kalmar, Sweden

${ }^{5}$ Department of Clinical Science, University of Bergen Faculty of Medicine and Dentistry, Bergen, Norway

Correction notice This article has been corrected since it first published. The provenance and peer review statement has been included.

Twitter Hege Andersen Amofah @AmofahHege and Tone M. Norekvål @TNorekval

Acknowledgements The authors thank the patients who shared their experiences.

Collaborators The CARDELIR Investigators

Contributors HAA, II and TMN were responsible for the study concept and design. HAA and II performed the data collection. HAA, AB, II, BF and TMN conducted the analysis and interpretation of data. HAA wrote the initial draft of manuscript supported by II and TMN. AB, BF, RH, KK and AHR performed critical revision of manuscript. HAA, II and TMN had full access to all of the data (including statistical reports and tables) in the study and take responsibility for the integrity of the data and the accuracy of the data analysis.

Funding This work was supported by Bergen Health Trust, Haukeland University Hospital. Recruitment for the CARDELIR study was also supported by the University of Bergen, Kavli Research Center for Aging and Dementia at Haraldsplass Deaconess Hospital, Western Norway University of Applied Sciences Bergen and the Norwegian Nurses' Association. Grant numbers are not applicable.

Disclaimer The funding bodies had no role in the design of the study, the collection, analysis, and interpretation of data, or in writing the manuscript.

Competing interests None declared.

Patient and public involvement Patients and/or the public were not involved in the design, or conduct, or reporting, or dissemination plans of this research.

Patient consent for publication Not required.

Ethics approval CARDELIR was approved by the Regional Committee for Ethics in Medical Research (REK Vest 2010/2936-6) and conducted in accordance with the Declaration of Helsinki. Patients provided informed written consent after receiving oral and written information about the study. The consent form also explained that participants had the right to withdraw at any time. Due to the patients' old age and the nature of the procedure, the interviewers had to be particularly alert to verbal and non-verbal signs that might suggest displeasure or exhaustion during data collection.

Provenance and peer review Not commissioned; externally peer reviewed.
Data availability statement Data are available upon reasonable request. The full interviews generated and analysed during the current study are not publicly available due to individual privacy issues but parts are available from the corresponding author on reasonable request.

Open access This is an open access article distributed in accordance with the Creative Commons Attribution Non Commercial (CC BY-NC 4.0) license, which permits others to distribute, remix, adapt, build upon this work non-commercially, and license their derivative works on different terms, provided the original work is properly cited, appropriate credit is given, any changes made indicated, and the use is non-commercial. See: http://creativecommons.org/licenses/by-nc/4.0/.

\section{ORCID iDs}

Hege Andersen Amofah http://orcid.org/0000-0002-1219-4880

Tone M. Norekvål http://orcid.org/0000-0003-3640-2119

\section{REFERENCES}

1 Zapolanski A, Mak AWC, Ferrari G, et al. Impact of New York heart association classification, advanced age and patient-prosthesis mismatch on outcomes in aortic valve replacement surgery. Interact Cardiovasc Thorac Surg 2012;15:371-6.

2 Rich MW, Chyun DA, Skolnick AH. Knowledge gaps in cardiovascular care of older adults: a scientific statement from the American heart association, American College of cardiology, and American geriatrics Society: executive summary. J Am Geriatr Soc 2016.

3 Astin F, Horrocks J, McLenachan J, et al. The impact of transcatheter aortic valve implantation on quality of life: a mixed methods study. Heart \& Lung 2017;46:432-8.

4 Witlox J, Eurelings LSM, de Jonghe JFM, et al. Delirium in elderly patients and the risk of Postdischarge mortality, institutionalization, and dementia. JAMA 2010;304:443-51.

5 Eide LSP, Ranhoff AH, Fridlund B, et al. Comparison of frequency, risk factors, and time course of postoperative delirium in octogenarians after transcatheter aortic valve implantation versus surgical aortic valve replacement. Am J Cardiol 2015;115:802-9.

6 Liao W-C, Huang C-Y, Huang T-Y, et al. A systematic review of sleep patterns and factors that disturb sleep after heart surgery. J Nurs Res 2011;19:275-88.

7 Amofah HA, Broström A, Fridlund B, et al. Sleep in octogenarians during the postoperative phase after transcatheter or surgical aortic valve replacement. Eur J Cardiovasc Nurs 2016;15:168-77.

8 Araújo T, Jarrin DC, Leanza Y, et al. Qualitative studies of insomnia: current state of knowledge in the field. Sleep Med Rev 2017;31:58-69.

9 Hashem MD, Nallagangula A, Nalamalapu S, et al. Patient outcomes after critical illness: a systematic review of qualitative studies following hospital discharge. Crit Care 2016;20:345.

10 Sterniczuk R, Rusak B, Rockwood K. Sleep disturbance in older ICU patients. Clin Interv Aging 2014;9:969-77.

11 Flannery AH, Oyler DR, Weinhouse GL. The impact of interventions to improve sleep on delirium in the ICU: a systematic review and research framework. Crit Care Med 2016;44:2231-40.

12 Inouye SK, Westendorp RGJ, Saczynski JS. Delirium in elderly people. Lancet 2014;383:911-22.

13 Galyfos GC, Geropapas GE, Sianou A, et al. Risk factors for postoperative delirium in patients undergoing vascular surgery. $J$ Vasc Surg 2017;66:937-46.

14 Eide LSP, Ranhoff AH, Fridlund B, et al. Readmissions and mortality in delirious versus non-delirious octogenarian patients after aortic valve therapy: a prospective cohort study. BMJ Open 2016;6:e012683.

15 Martin JL, Fung CH. Quality indicators for the care of sleep disorders in vulnerable elders. $J$ Am Geriatr Soc $2007 ; 55:$ S424-30.

16 Inouye SK, Bogardus ST, Charpentier PA, et al. A multicomponent intervention to prevent delirium in hospitalized older patients. N Engl $J$ Med 1999;340:669-76.

17 Tong A, Sainsbury P, Craig J. Consolidated criteria for reporting qualitative research (COREQ): a 32-item checklist for interviews and focus groups. Int J Qual Health Care 2007;19:349-57.

18 Inouye SK, van Dyck CH, Alessi CA. Clarifying confusion: the confusion assessment method. A new method for detection of delirium. Ann Intern Med 1990;113:941-8.

19 Folstein MF, Folstein SE, McHugh PR. A practical method for grading the cognitive state of patients for the clinician. J Psychiatric Res 1975;12:189-98

20 Broström A, Hübbert L, Jakobsson P, et al. Effects of long-term nocturnal oxygen treatment in patients with severe heart failure. $J$ Cardiovasc Nurs 2005;20:385-96. 
21 Hellström A, Hagell P, Fagerström C, et al. Measurement properties of the minimal insomnia symptom scale (miss) in an elderly population in Sweden. BMC Geriatr 2010;10:84

22 Eide LS, Ranhoff AH, Lauck S, et al. Indwelling urinary catheters, aortic valve treatment and delirium: a prospective cohort study. BMJ Open 2018;8:e021708.

23 Instenes I, Gjengedal E, Eide LSP. "Eight days of nightmares" Octogenarian patients' experiences of postoperative delirium after transcatheter or surgical aortic valve replacement. . Heart Lung Circ 2018;27:260-6.

24 Graneheim UH, Lundman B. Qualitative content analysis in nursing research: concepts, procedures and measures to achieve trustworthiness. Nurse Educ Today 2004:24:105-12.

25 Smagula SF, Stone KL, Fabio A, et al. Risk factors for sleep disturbances in older adults: evidence from prospective studies. Sleep Med Rev 2016;25:21-30.

26 Bannon L, McGaughey J, Clarke M, et al. Impact of nonpharmacological interventions on prevention and treatment of delirium in critically ill patients: protocol for a systematic review of quantitative and qualitative research. Syst Rev 2016;5:75.
27 Kamdar BB, King LM, Collop NA, et al. The effect of a quality improvement intervention on perceived sleep quality and cognition in a medical ICU*. Crit Care Med 2013;41:800-9.

28 Patel J, Baldwin J, Bunting P, et al. The effect of a multicomponent multidisciplinary bundle of interventions on sleep and delirium in medical and surgical intensive care patients. Anaesthesia 2014;69:540-9.

29 Abdalla A, Adhaduk M, Haddad RA, et al. Does acute care for the elderly (ACE) unit decrease the incidence of falls? Geriatr Nurs 2018;39:292-5

30 Kamdar BB, Combs MP, Colantuoni E, et al. The association of sleep quality, delirium, and sedation status with daily participation in physical therapy in the ICU. Crit Care 2016;19:261.

31 Lauck SB, Kwon JY, Wood DA. Avoidance of urinary catheterization to minimize in-hospital complications after transcatheter aortic valve implantation: an observational study. Eur J Cardiovasc Nurs 2017;1474515117716590.

32 Desjardins S, Lapierre S, Hudon C, et al. Factors involved in sleep efficiency: a population-based study of community-dwelling elderly persons. Sleep 2019;42.

33 Schroeck JL, Ford J, Conway EL, et al. Review of safety and efficacy of sleep medicines in older adults. Clin Ther 2016;38:2340-72. 